\title{
Evidence of sustainable land use: the reclamation of desertified lands to plant vineyards
}

Liang Zhang ${ }^{1}$, Tingting Xue ${ }^{2}$, Feifei Gao ${ }^{1}$, Lin Yuan ${ }^{3}$, Zhilei Wang ${ }^{1}$, Ruteng Wei ${ }^{1}$, Xiaoyun $\mathrm{Hao}^{1}$, Chenlu Yang${ }^{1}$, Ying Wang ${ }^{1}$, Xing Han ${ }^{1}$, Lin Wang ${ }^{1}$, Yulei Han ${ }^{1}$, Hua $\mathrm{Li}^{4}$, and Hua Wang $^{1}$

${ }^{1}$ Northwest A\&F University

${ }^{2}$ Ningxia University

${ }^{3}$ China Agricultural University

${ }^{4}$ Northwest A

April 20, 2021

\begin{abstract}
Desertified land reclamation for the purposes of winegrape cultivation can profoundly alter the properties of the underlying soil and the microbial communities therein. Herein, we assessed the effects of such reclamation of non-productive desert land on the soil microbial communities associated with the resultant vineyards, and to identify key soil properties related to these changes. Soil was collected from natural desert land (DL) and from different reclaimed vineyard types: Cabernet Sauvignon (CS), Merlot (M), Chardonnay (C), and Italian Riesling (IR). High-throughput sequencing was used to assess microbial community composition and diversity in these samples. Significant differences in soil organic carbon (SOC), total nitrogen, available nitrogen, available phosphorus, and $\mathrm{pH}$ were detected when comparing soil from DL and reclaimed lands. CS, M, C, and IR soils exhibited higher relative Actinobacteria, Proteobacteria, and Ascomycota abundance, while DL soil exhibited higher relative Acidobacteria and Mortierellomycota abundance. In total, 165 and 55 bacterial and fungal amplicon sequence variants or operational taxonomic units (ASVs/OTUs) were shared across land use types. Following reclamation, soil bacteria ASVs/OTUs in CS, M, C, and IR soils rose to 2846, 3191, 7630, and 6373, respectively. Biomarkers of these different land use types were successfully identified via an LDA Effect Size (LEfSe) approach, while key soil properties including pH, SOC, and available nitrogen were found to be associated with these changes in microbial community structural composition following reclamation. As such, our data indicate that viticulture in desertified regions can enhance soil properties and microbial diversity, thereby supporting sustainable land use.
\end{abstract}

Evidence of sustainable land use: the reclamation of desertified lands to plant vineyards

Liang Zhang ${ }^{1}$, Tingting Xue ${ }^{2}$, Feifei Gao ${ }^{1}$, Lin Yuan $^{3}$, Zhilei Wang ${ }^{1}$, Ruteng Wei ${ }^{1}$, Xiaoyun Hao $^{1}$, Chenlu Yang ${ }^{1}$, Ying Wang ${ }^{1}$, Xing Han $^{1}$, Lin Wang ${ }^{1}$, Yulei Han ${ }^{1}$, Hua $\mathbf{L i}^{1,4,5^{*}}$, Hua Wang ${ }^{1,4,5^{*}}$

1 College of Enology, Northwest A\&F University, No. 22, Xinong Road, Yangling, Shaanxi 712100, PR China

2 School of Food \& Wine, Ningxia University, No.539, Helanshan West Road, Yinchuan, Ningxia 750021, PR China

3 College of Food Science \& Nutritional Engineering, China Agricultural University, No.17, Qinghua East Road, Beijing, 100083, PR China 
4 Shaanxi Engineering Research Center for Viti-Viniculture, No. 22, Xinong Road, Yangling, Shaanxi 712100, PR China

5 China Wine Industry Technology Institute, Zhongguancun innovation Center, Yinchuan, Ningxia 750021, PR China

*Correspondence authors: Hua Li \& Hua Wang

Email: lihuawine@nwsuaf.edu.cn (H.Li); wanghua@nwsuaf.edu.cn (H. Wang)

\section{Abstract}

Desertified land reclamation for the purposes of winegrape cultivation can profoundly alter the properties of the underlying soil and the microbial communities therein. Herein, we assessed the effects of such reclamation of non-productive desert land on the soil microbial communities associated with the resultant vineyards, and to identify key soil properties related to these changes. Soil was collected from natural desert land (DL) and from different reclaimed vineyard types: Cabernet Sauvignon (CS), Merlot (M), Chardonnay (C), and Italian Riesling (IR). High-throughput sequencing was used to assess microbial community composition and diversity in these samples. Significant differences in soil organic carbon (SOC), total nitrogen, available nitrogen, available phosphorus, and $\mathrm{pH}$ were detected when comparing soil from DL and reclaimed lands. CS, M, C, and IR soils exhibited higher relativeActinobacteria , Proteobacteria, and Ascomycotaabundance, while DL soil exhibited higher relative Acidobacteria and Mortierellomycota abundance. In total, 165 and 55 bacterial and fungal amplicon sequence variants or operational taxonomic units (ASVs/OTUs) were shared across land use types. Following reclamation, soil bacteria ASVs/OTUs in CS, M, C, and IR soils rose to 2846, 3191,7630 , and 6373 , respectively. Biomarkers of these different land use types were successfully identified via an LDA Effect Size (LEfSe) approach, while key soil properties including $\mathrm{pH}$, SOC, and available nitrogen were found to be associated with these changes in microbial community structural composition following reclamation. As such, our data indicate that viticulture in desertified regions can enhance soil properties and microbial diversity, thereby supporting sustainable land use.

\section{Keywords}

winegrape cultivation, microbial community, high-throughput sequencing, soil properties, sustainable land use

\section{INTRODUCTION}

Desertified reclamation for irrigated agricultural use is increasingly necessary to meet with the needs of a growing global population, and large swathes of reclaimed farm and forest land have thus been established throughout the world (Salama, Abd El-Ghani, El-Tayeh, Amro, \& Abdrabbu, 2017; Yang et al., 2019). The reclamation of desertified land to generate economic forest lands has been practiced in regions of Northwest China such as the Hongsibu District in Ningxia. This region experiences a very dry climate and significant temperature variability depending on the time of day such that few crops can reliably grow in this area. However, winegrapes can grow well under these conditions, leading to their increasingly widespread cultivation and rising incomes for grape-growers. Through concerted desertified land reclamation efforts over the past two decades in Hongsibu, the winegrape cultivation area had risen to $7067 \mathrm{hm}^{2}$ as of 2018 (Statistics of Ningxia Wine Bureau). These land reclamation efforts result in well-documented changes in soil quality attributable to changes from desert soil to irrigated cropland (Ferreira, Leite, de Araújo, \& Eisenhauer, 2016; Tosi et al., 2016). Crop cultivation, however, can also reduce certain aspects of soil quality including soil organic carbon (SOC) and nitrogen levels (Liu et al. 2005; Bhattacharyya et al., 2014; Sharma et al., 2017), in addition to altering the composition of soil microbial communities (Crecchio et al., 2007). Exploring how soil properties change following crop planting is essential to more fully assess the relative success of different land reclamation strategies in order to support sustainable land management efforts.

Soil quality is an integrative concept regulated by the physical, chemical, and biological properties of the soil (Oliver, Bramley, Riches, Porter, \& Edwards, 2013). Bulk soil density, porosity, soil organic matter/SOC 
content, $\mathrm{pH}$, and available nutrient levels are among the most commonly used metrics to gauge such soil quality (Bünemann et al., 2018; Morvan et al., 2008; Mouazen, Steffens, \& Borisover, 2016). Changes in soil properties following reclamation are vital to the monitoring of sustainable land use. Microbial diversity in the context of desertified soils, however, is not well documented and must be further studied to more fully clarify how winegrape planting impacts the properties of the underlying soil.

Reclamation-related shifts in soil microbial communities can be positive or negative depending upon the landuse type. For example, converting land use from a natural ecosystem to a managed agricultural ecosystem can adversely impact soil microbial diversity (Thomson et al., 2015), whereas the conversion of lands with extreme conditions such as high salinity or aridity into cropland can positively impact associated microbial communities (Wang et al., 2012). Many reports have demonstrated the effects of land-use changes on soil microbial community composition and diversity in very arid environments, with several soil properties being closely linked to these microbial shifts. For example, alterations in soil $\mathrm{pH}$ and moisture content were shown to be related to bacterial communities therein following 30 years of agricultural practice in desert soil in Egypt (Köberl, Müller, Ramadan, \& Berg, 2011). In the Atacama Desert, soil relative humidity was also the primary determinant of microbial community richness and diversity (Neilson et al., 2017). These findings emphasized the overriding impact of water availability and related soil properties on microbial community composition in the context of improving soil quality and productivity in arid regions throughout the world. The Yellow River flows through Ningxia, and owing to the Yellow River Irrigation Project, water is not a major limiting factor associated with soil quality, whereas high salinity, low organic matter, and nutrient levels are likely to be important regulators of microbial community composition and associated shifts in productivity (Cheng, Chen, \& Zhang, 2019). Further studies regarding these concomitant changes in soil properties and microbial communities in these desertification areas are thus necessary to ensure sustainable land use.

Soil microbial communities are highly sensitive to variations in soil physicochemical properties (Franco-Otero, Soler-Rovira, Hernández, López-de-Sá, \& Plaza, 2012) and land use alterations (Szoboszlay, Dohrmann, Poeplau, Don, \& Tebbe, 2017; Tosi et al., 2016; Wu et al., 2017). Recent research suggests that sustained monocropping can reduce the diversity of soil microbial communities and can interfere with soil microbial community structure (Ellouze et al., 2014; Li, Ding, Zhang, \& Wang, 2014). In one study, bacterial richness and diversity were shown to rise following the conversion of desert land to 5-year-old cropland, and thereafter remained stable following 5 years of cotton cropping ( $\mathrm{Li}$ et al., 2020). Land-use type can profoundly shape soil bacterial community composition and diversity owing to the resultant shifts in soil chemical properties, particularly in the context of desertified land reclamation (Li, Pokharel, Liu, \& Chen, 2020). There have been few studies to date, however, assessing changes in soil microbial communities and associated soil parameters after desert land reclamation for viticulture.

Herein, we evaluated soil microbial community composition and diversity in vineyards following the reclamation of desertified land in Hongsibu in Northwest China, with the goal of providing a theoretical foundation for sustainable land use efforts. We hypothesized that: (a) soil microbial communities would be significantly altered following desertified land reclamation in a manner associated with the types of grapes grown in different vineyards, and (b) that soil microbial community composition in these reclaimed lands is attributable to the soil chemical properties (such as $\mathrm{pH}$, SOC, nitrogen, and phosphorus levels) associated with these different land use types.

\section{MATERIALS AND METHODS2.1 Study area}

This study was conducted in the Huida Chateau and Xiaojiayao winegrapes planting area in the Hongsibu District of Northwest China (Figure 1). Hongsibu is the largest wine-growing sub-area in the eastern region of the Helan Mountains, which is a wine region with a nationally protected geographical indication. While previously dominated by natural desert land (DL) populated by a small number of salt-tolerant plants able to grow under arid conditions including Populus L. ,Zygophyllaceae, Ulmusglaucescens, Leguminosae, andElaeagnaceae (Xu, Wang, Jia, \& Guo, 2020), the reclamation of this land in the 1990s has led to its use for crop growth. Winegrapes are the crop best-suited to growing in this region owing to its arid conditions 
and substantial diurnal temperature variability.

The study site was situated within a mountain basin with an area of $2,767 \mathrm{~km}^{2}$ at an altitude of 1,240 - 1,450 $\mathrm{m}$ with a typical temperate continental climate. The region remains dry throughout the year with an average annual precipitation of $251 \mathrm{~mm}$, an average annual evaporation of $2,387 \mathrm{~mm}$, an average annual temperature of $8.7^{\circ} \mathrm{C}$, a daily temperature difference of $13.7^{\circ} \mathrm{C}$, a sum of accumulated effective temperatures ([?]10degC) above $3,200 \mathrm{degC}, 2,900-3,550 \mathrm{~h}$ of annual sunshine, and an averageannual wind speed of $2.9-3.7 \mathrm{~m} / \mathrm{s}$. The soil exhibits a sandy loam texture (50\% clay, $30 \%$ silt, and $20 \%$ sand). The same type of soil was used in the desertified land reclamation associated with all studied vineyards, which are regularly managed, with plants arranged in north-south rows at a row spacing of $3 \mathrm{~m}$, a vine spacing of $0.5 \mathrm{~m}$, and cultivation mode of single cane 'Dulonggan', only Italian Riesling cultivation mode of Crawled Cordon Training. Annual fertilization amounts include an estimated $40.18 \mathrm{~kg} / \mathrm{hm}^{2}$ of nitrogen fertilizer, $30.21 \mathrm{~kg} / \mathrm{hm}^{2}$ of phosphate fertilizer, $8.68 \mathrm{~kg} / \mathrm{hm}^{2}$ of potassium fertilizer, and $22.18 \mathrm{~kg} / \mathrm{hm}^{2}$ of organic manure, while the annual irrigation water volume is $4000 \mathrm{~m}^{3} / \mathrm{hm}^{2}$.

\subsection{Experimental design and soil sampling}

Winegrape croplands reclaimed from desert land in 2012, 2014, and 2017 were selected for the present study in 2020, with crops of Cabernet Sauvignon (CS), Italian Riesling (IR), Merlot (M), and Chardonnay (C) grapes having been planted $8,6,3$, and 3 years following reclamation, respectively. Undisturbed, non-cultivated desertified soil was collected at two research sites adjacent to these vineyards, and the same amount of soil from each site was evenly mixed following collection. The distance between these two sampling sites varied from $0.5-3 \mathrm{~km}$.

In September 2020, three replicate 10 x $10 \mathrm{~m}$ plots separated by at least $100 \mathrm{~m}$ were established. Within each plot, a $0-20 \mathrm{~cm}$ rhizosphere soil sample was collected using a steel corer $(5 \mathrm{~cm}$ diameter) following surface litter removal. In total, 10 random cores were collected per plot and combined into a single composite sample. Three samples of undisturbed soil were taken from the middle of these cores ( $\sim 10 \mathrm{~cm}$ depth) to assess soil bunk density using a corer $\left(5 \mathrm{~cm}\right.$ diameter; $\left.100 \mathrm{~cm}^{3}\right)$. Soil samples were sealed into plastic bags and kept on ice while in transit. In the laboratory, samples were passed through a $2 \mathrm{~mm}$ sieve to remove coarse matter and plant debris, after which samples were split into two parts, one of which was air-dried for physicochemical analyses and the other of which was stored at -80degC and used for DNA isolation within 1 week.

\subsection{Soil physicochemical analyses}

After soil had been dried to a constant weight at $105 \mathrm{degC}$, its bulk density was established. Soil $\mathrm{pH}$ was measured at a water-soil ratio of 2.5:1 without any $\mathrm{CO}_{2}$ water extraction via a potentiometric method. Total nitrogen (TN) was assessed via the micro-Kjeldahl method (Lu 1999). Soil available nitrogen was quantified via an alkaline hydrolysis diffusion approach (Bao 2000). Soil ammonium nitrogen $\left(\mathrm{NH}_{4}{ }_{-}-\mathrm{N}\right)$ and nitratenitrogen $\left(\mathrm{NO}_{3}{ }^{-}-\mathrm{N}\right)$ were leached with a $2 \mathrm{~mol} / \mathrm{L}$ potassium chloride solution and then measured via flow injection analysis. Soil total phosphorus and available phosphorus were quantified using a molybdenumantimony anti-colorimetric approach (Bao 2000). Soil total organic carbon was assessed via an external heating method using potassium dichromate (Carter \&Gregorich, 2007). A flame photometer approach was employed to measure total potassium content, while available potassium was quantified via an ammonium acetate extraction-flame photometric method (Bao 2000; Smith \& Bain, 1982).

\subsection{DNA extractionand sequencing}

An OMEGA Soil DNA Kit (Catalog number D5625-01) was used to extract soil DNA, and DNA concentrations were measured with a UV-visible spectrophotometer (Thermo Scientific, DE, USA). DNA quality was assessed via $0.8 \%$ agarose gel electrophoresis. The V3 andV4 bacterial 16s rRNA hypervariable regions were amplified with the 5'-ACTCCTACGGGAGGCAGCA-3' forward primer and the 5'CGGACTACHVGGGTWTCTAAT-3' reverse primer. Additionally, the V1 hypervariable region of the fungal ITS gene was amplified with the 5'-GGAAGTAAAAGTCGTAAGG-3' forward primer and the 5'- 
GCTGCGTTCTTCATCGATGC-3' reverse primer. A sequencing library was constructed with the TruSeq Nano DNA LT Library Prep Kit (Illumina). After library quality had been assessed, community DNA fragments were analyzed via paired-end sequencing using an Illumina MiSeq instrument by Shanghai Peisenol Biotechnology Co., Ltd.

\subsection{Data processing}

Raw high-throughput sequencing data were initially assessed to measure sequence quality. Samples were separated into libraries according to barcode information, and barcode sequences were removed. Those sequences $>200 \mathrm{bp}$ in length with a mean quality score [?] 20 were retained for further analysis. Primer removal, mass filtration, denoising, splicing, and the removal of chimeric sequences were conducted via the DADA2 method (Callahan et al., 2016). Rather than performing similarity-based clustering, this approach only consisted of de-replication. Amplicon sequence variants (ASVs) or operational taxonomic units (OTUs) were generated according to the QIIMA2 DADA2 quality control results. After rarefaction-based normalization to the same sequencing depth ( $95 \%$ of the lowest sample sequence depth), ASVs/OTUs were predicted for each sample along with relative abundance at that sequencing depth (Kemp, \& Aller, 2004).

\subsection{Statistical analyses}

Data normality and homogeneity of the variance were respectively analyzed via the Shapiro-Wilk and Levene's tests, after which soil properties were compared by conducting one-way ANOVAs. Venn diagrams were used to identify shared and unique ASVs/OTUs associated with different land-use types. Observed species, Chao1, Shannon, and Simpson indices were used to assess the diversity and richness of soil microbial communities at the ASV/OTU level (Qiao, Zhang, Shi, Song, \& Bian, 2018). A nonmetric multidimensional scaling (NMDS) approach was employed to assess differences in soil microbial communities across all soil sample types based upon Bray-Curtis distances, with similarities between samples being displayed via hierarchical clustering analyses. A permutational multivariate analysis of variance (PERMANOVA) approach was used to test for differences in soil microbial composition as a function of land-use type based upon the adonis test (Anderson, 2001; McArdle, \& Anderson, 2001). LDA Effect Size (LEfSe) was employed to identify land-use type-related biomarkers (Segata et al., 2011). A redundancy analysis (RDA) was performed to examine correlations between microbial communities and soil chemical properties using Canoco 5.0. Pearson correlation analyses were conducted to examine relationships between soil properties and microbial communities. R, QIIME 2.0, and SPSSS 24.0 were used for all analyses.

\section{RESULTS3.1 Soil properties}

Significant differences in soil chemical properties were observed as a function of land-use type (Table 1). DL soils exhibited a significantly higher bulk density relative to other land-use types, whereas DL soil had the lowest levels of TN and available potassium (Table 1). TN levels were highest in C soils $\left(0.40 \mathrm{~g} \mathrm{~kg}^{-1}\right)$, while available nitrogen was the highest in CS soils $\left(37.63 \mathrm{mg} \mathrm{kg}^{-1}\right)$, and TN levels were significantly higher in CS, M, C, and IR soil samples relative to DL samples $(p<0.05)$. Available phosphorus levels were highest in DL soil $\left(7.86 \mathrm{mg} \mathrm{kg}^{-1}\right)$, with significant differences in available phosphorus in the CS, M, C, IR, and DL samples $(p<0.05)$ without any concomitant differences in TP. TK exhibited a downward trend from CS, M, C to IR, and then rose to DL. Available potassium levels in CS, M, C, and IR samples were 1.44, 1.42, 1.37, and 1.13 times those in DL samples. The TN, SOC, and $\mathrm{pH}$ of CS, M, C, and IR soil samples were all significantly higher than those in DL samples $(p<0.05)$.

\subsection{Bacterial and fungal taxa distributions in soils associated with different land-use types}

In total, 1,942,867 original sequences and 1,693,153 effective sequences were derived from the 16S_V3V4 region in sequences soil samples, while 1,233,294 original sequences and 1,085,213 effective sequences were obtained from the ITS_V1 region. In total, 165 bacterial ASVs/OTUs were found to be shared across all five land-use types, with the numbers of unique bacterial ASVs/OTUs in these soil samples being rank-ordered as follows: C > IR > M > CS > DL. Following reclamation, soil bacterial ASVs/OTUs in the CS, M, C, and IR samples rose to $2846,3191,7630$, and 6373 , respectively. A total of 55 shared fungal ASVs/OTUs were 
detected across land-use types, while numbers of unique fungal ASVs/OTUs associated with these different land-use types were, in rank-order: IR $>\mathrm{M}>\mathrm{CS}>\mathrm{C}>\mathrm{DL}$. Following desertified land reclamation, the number of soil fungi present in CS, M, and IR vineyards rose to 788, 984, and 1114, respectively, but the number of fungi in $\mathrm{C}$ was lower than in DL (Figure 2).

Actinobacteria (33.58\%), Proteobacteria (30.71\%),Acidobacteria (12.67\%), Chloroflexi (8.20\%), Gemmatimonadetes (6.17\%), Firmicutes (2.65\%),Bacteroidetes (1.57\%), and Rokubacteria (1.14\%) were the most abundant bacterial phyla in analyzed soil samples (Figure 3a).Actinobacteria and Proteobacteria were the dominant phyla in CS, M, C, and IR soils, whereas Actinobacteria (24.08\%),Proteobacteria (22.47\%), and Acidobacteria (25.74\%) were dominant in DL soils. Relative Actinobacteria andProteobacteria abundance in CS, M, C, and IR soils was higher than that observed in DL soils. Relative Chloroflexi abundance was significantly higher in CS, C, and IR soils relative to DL soils $(p<0.05)$, whereas Acidobacteria andFirmicutes abundance was significantly lower in CS, M, C, and IR soils relative to DL soils $(p<0.05)$.

Ascomycota (71.50\%), Basidiomycota (8.87\%), Mortierellomycota (5.87\%),Mucoromycota(0.86\%), and Rozellomycota $(0.17 \%)$ were the most dominant fungi in analyzed soil samples (Figure 3b), with Ascomycota ,Basidiomycota, and Mortierellomycota being the most dominant phyla associated with different land-use types. Relative to DL samples, the relative abundance of Ascomycota in CS, M, C, and IR samples rose by $5.45 \%, 6.06 \%, 34.47 \%$, and $21.59 \%$, respectively. Ascomycota abundance was significantly higher in C and IR soils relative to DL soil $(p<0.05)$. Basidiomycotalevels were significantly higher in CS and M soils relative to DL soil $(p<0.05)$, whereas Mortierellomycota abundance was significantly lower in M, C, and IR samples relative to DL soils $(\mathrm{p}<0.05)$.

3.3 Bacterial and fungal community diversity

Next, bacterial richness and diversity in soils associated with different land-use types were measured using the Chao1, Observed species, Shannon, and Simpson indices (Table 2). The rhizosphere bacterial abundance (Observed species) for the four vineyard soil types was significantly higher than that in DL samples, while bacterial abundance in C and IR samples (Chao1) was significantly higher than that in DL soil $(p<0.05)$. Relative to DL soils, the bacterial diversity (Shannon) in C and IR samples was significantly increased $(p<$ 0.05), while the Simpson index was significantly increased in CS and C samples. Relative to DL soil samples, viticultural land use was associated with increased soil fungal diversity in all soil types other than the $\mathrm{C}$ soil (Table 2).

The NMDS ordination of bacteria and fungi are 0.0837 and 0.0999 , respectively, with both of these values being less than 0.2, consistent with good analysis results (Figure 4). NMDS revealed clear separation in bacterial composition across land-use types with the exception of CS and M samples, with close clustering of the community composition profiles associated with these two land-use types.

Hierarchical clustering analyses were then performed using the Bray Curtis distance algorithm, revealing that bacteria in vineyard soil samples were clustered together and separated from those in DL soil (Figure 5a). Similarly, for fungal communities, all vineyard soil samples were separated from all DL soil samples other than sample $\mathrm{DL}_{2}$ (Figure $5 \mathrm{~b}$ ). These data suggested that microbial community structure differed significantly when comparing vineyard soils to DL soils.

A PERMANOVA analysis revealed significant differences in soil bacterial composition rankings for different land-use types $\left(\mathrm{R}^{2}=0.65, p=0.001\right)$, with the same also being observed for soil fungal community composition rankings $\left(\mathrm{R}^{2}=0.58, p=0.001\right)$ (Table 3). LEfSe analysis results indicated that bacteria that differed significantly between land-use types at the class level included Chloroflexi, Fibrobacteres, Firmicutes

, Gemmatimonadetes, Patescibacteria ,Proteobacteria, and Rokubacteria (Figure 6a), with further details regarding differences at other taxonomic levels being further detailed in the corresponding Figure. Fungi that differed significantly between land-use types at the class level included Rozellomycota, Trichothecium , Eremomycetaceae, and Selenophoma(Figure 6b), with further details being shown in the corresponding Figure. 


\subsection{Associations between soil bacterial and fungi communities, diversity, and soil chemical properties}

Pearson correlation analyses revealed that several soil chemical properties were correlated with bacterial and fungal diversity (Table S). TN was positively correlated with bacteria Chao1 $(\mathrm{r}=0.558, p<0.05)$, Observed species $(\mathrm{r}=0.562, p<0.05)$, and Shannon index values $(\mathrm{r}=0.627, p<0.05)$. Soil nitrate-nitrogen was significantly positively correlated with bacteria Chao1 $(\mathrm{r}=0.970, p<0.01)$, Observed species $(\mathrm{r}=0.970, p<0.01)$, and Shannon index values $(\mathrm{r}=0.823, p<0.01)$. Soil ammonium nitrogen was significantly positively correlated with bacteria Chao1 $(\mathrm{r}=0.812, p<0.01)$, Observed species $(\mathrm{r}=0.823, p<0.01)$, and Shannon index values $(\mathrm{r}=0.701, p<0.01)$. SOC and $\mathrm{pH}$ were positively correlated with bacterial Chao1 and Observed species index values.

An RDA analysis was then performed to assess the relationships between soil chemical properties and the composition of soil fungal and bacterial communities at the phyla level (Figure 7). The proportion of the total variance in these bacterial communities explained by all eight measured soil chemical parameters analyzed in this study was $82.91 \%$ (Figure 7a). The first constraint axis (RDA1) explained $54.25 \%$ of this variance, while the second (RDA2) explained $28.66 \%$ of the total variance. Overall, $\mathrm{pH}$ explained $42.20 \%(p=0.004)$ of total variance in bacterial community composition, followed by available nitrogen $(14.10 \%, p=0.032)$. The measured soil chemical parameters in the present study similarly explained $73.97 \%$ of the total variance in soil fungal communities (Figure 7b). The first constraint axis (RDA1) explained $71.35 \%$ of this variance, while the second (RDA2) explained $2.64 \%$ of this variance. Additionally, $\mathrm{pH}$ explained $31.50 \%$ of the total variance $(p=0.014)$, followed by available phosphorus, available nitrogen, and SOC.

\section{DISCUSSION}

Herein, we found that desertified land reclamation for viticulture was associated with significant changes in soil microbial communities and soil properties, consistent with our hypotheses. Such land reclamation was associated with significant increases in SOC relative to that observed in DL soil, consistent with the land conversion to vineyards having increased soil organic matter content. Organic matter inputs include winegrape litter, which can additionally contribute to the soil nutrient content as well as fertilizer and manure applied in the context of viticulture, thereby contributing to SOC and nutrient availability. C soil samples exhibited the highest SOC levels (Table 1), likely because the soil is less disturbed in these fields and because the plant leaves contain secondary metabolites such as tannins, terpenes, and polyphenols that slow the rate of litter decomposition. Yanget al. (2016) have also previously reported reclamation-related increases in $\mathrm{SOC}$ and nutrient contents. We found that DL reclamation for winegrape cultivation was associated with a significant increase in rhizosphere soil pH (Table 1), in contrast to prior study results (Djukic, Zehetner, Tatzber, \& Gerzabek, 2010; Franco-Otero, Soler-Rovira, Hernandez, Lopez-de-Sa, \& Plaza, 2012), potentially due to study site-specific differences. Indeed, the soil alkalinity in the Hongsibu area of Ningxia in this study was higher than in the previous studies.

Winegrape planting was associated with a reduction in soil volume that may be attributable to the long-term plowing associated with the viticulture process. Similar changes in TN and SOC were also observed, whereas TP and TK did not differ significantly among the five analyzed land-use applications, potentially owing to the high phosphorus and potassium content of desertified soil minerals (Hendrix, 2000; Ma, Sun, Sun, \& Wang, 2012; Gong, He, \& Liu, 2016). Soil available potassium rose significantly following reclamation, consistent with SOC accumulation. In contrast, soil available nitrogen and available phosphorus content decreased significantly after reclamation, likely due to the absorption of these nutrients by grape plants at a rate greater than that at which fertilized nitrogen and phosphorus were applied (Gong, He, \& Liu, 2016). Soil nutrient contents observed in this study were generally lower than those reported in other regions (Dominguez, Panettieri, Madejon, \& Madejon, 2020), consistent with the fact that winegrapes are suited to cultivation in regions with harsh ecological conditions and relatively poor soil conditions.

The composition and diversity of bacterial communities in a given ecosystem can change in response to environmental variation (Cheng, Chen, \& Zhang, 2018). We therefore hypothesized that bacterial community would differ significantly when comparing DL and reclaimed soils, and confirmed that this was true at 
the taxa level (Figure 2; Figure 3), through NMDS analyses (Figure 4), and via a hierarchical clustering analysis (Figure 5). We observed distinct differences in the relative abundance of top bacterial phyla among land-use types, indicating that DL reclamation was linked to altered microbial community composition. Actinobacteria were the most abundant bacterial phyla in the present study, and Actinobacteria abundance was significantly higher in CS, M, C, and IR soils relative to DL soils, consistent with prior reports (Gao et al., 2020). While pesticide use in vineyards can impact soil bacterial communities, Actinobacteria, which degrade hydrocarbons and pesticides (Alvarez et al., 2017), are not impacted by pesticides. Proteobacteria were also dominant in the present study, with higher relative Proteobacteria abundance in reclaimed soil relative to DL soil. Relative Proteobacterialevels were significantly higher in M and IR soil samples relative to DL soil samples, potentially due to the higher sulfur levels in vineyards. Sustained livestock organic fertilizer application and the input of organic matter in M and IR vineyards can contribute to these increases in soil sulfur levels. Indeed, shifts in Deltaproteobacteriaabundance have been linked to changes in soil sulfur content (Wasmund, Mussmann, \& Loy, 2017). We also observed reclamation-related changes in the abundance of Acidobacteria, which are frequently reported to be regulated by soil pH (Ramirez et al., 2014). In line with the results of a prior study (Lauber, Hamady, Knight, \&Fierer 2009), we found that relative Acidobacteria abundance declined with rising soil $\mathrm{pH}$. We additionally found that bacterial abundance (Chao1) and diversity (Shannon) in C and IR soils were significantly increased relative to DL soils (Table 2), owing to differences in soil chemical properties.

With respect to soil fungal community composition and diversity, we found that Ascomycota was the dominant phylum among the analyzed land-use patterns, followed by Basidiomycota, in line with prior reports (Maestre et al., 2015; Porras-Alfaro, Herrera, Natvig, Lipinski, \& Sinsabaugh, 2011; Prober et al., 2015). We found that winegrape cultivation was associated with increased fungal diversity, although there were no significant differences in fungal diversity indices associated with different land use types (Table 2). This may be because Bordeaux and lime sulfur mixtures are applied to these vineyards to prevent fungal diseases, thereby reducing fungal diversity, whereasAscomycota species can tolerate harsher conditions (Chen et al., 2017). NMDS and hierarchical clustering results indicated that microbial community structures differed significantly in cultivated soils relative to DL soils, but the bacterial and fungal community structure was similar in CS and M (Figure 4; Figure 5). This may be a result of changes in land-use that led to similar root exudate and litter properties in CS and M soils, thus inducing similar rhizosphere bacterial and fungal community structures. However, the bacterial and fungal community structures differed significantly in $\mathrm{M}$ and $\mathrm{C}$ samples, both of which were 3 years old, indicating that the microbial community structure differences in the context of short-term cultivation (for less than 5 years) were more closely related to winegrape cultivar type. In addition, LEfSe analyses directly assess differences at all taxonomic levels at once, and can identify differences in species between groups as biomarkers of a particular sample type (Figure 6). These biomarkers may contribute to long-term sustainable reclaimed land use, although further study of this topic is required.

Soil microbial diversity is crucial to ensuring long-term soil ecosystem sustainability (Cheng et al., 2017; Maron et al., 2018). Assessing soil microbial diversity in a reclamation ecosystem can thus offer perspectives on long-term sustainable development strategies for reclaimed desert land. Herein, we found that bacterial and fungal ASVs/OTUs (Figure 2) and diversity index (Table 3) were higher in reclaimed vineyard soils relative to DL soil samples. These changes were attributed to increased organic matter input in the reclaimed soil owing to cultivation-related fertilizer application and associated crop residues. However, we did find that when analyzing fungal ASVs/OTUs, the Chao1, and Observed species index values in C soils were lower than in DL soils, suggesting a decrease in mycorrhizal dependence associated with Chardonnay grape cultivation. Winegrape cultivation is thus generally associated with increased fungal and bacterial diversity owing to the increased diversity of plants in the vineyard rows (Kowalchuk, Buma, de Boer, Klinkhamer, \& Van Veen, 2002). Plant diversity and associated rhizosphere carbon input can help drive increased soil microbial diversity (Lange et al., 2015; Meng et al., 2019). Higher microbial diversity is often associated commonly linked to increased ecosystem stability (Delgado-Baquerizo et al., 2016). Therefore, a viticulture model of interrow grass planting with higher plant diversity should be adopted to facilitate the sustainable development of land use in desertification areas. 
Several prior reports have demonstrated the important link between soil chemistry and microbial community composition in a variety of ecosystems (Kerfahi, Tripathi, Dong, Go, \& Adams, 2016; Nanganoa et al., 2019; Tian et al., 2017). SOC, pH, and nutrient contents have been reported to be the key determinants of bacterial community composition and diversity in vineyards ( $\mathrm{Li}, \mathrm{Chi}, \mathrm{Li}, \mathrm{Wu}, \&$ Yan, 2019). Our correlation analyses revealed SOC, ammonium, nitrate, and bacterial diversity indices to be positively correlated (Table S). As such, the increase in SOC levels in reclaimed soil may contribute to elevated bacterial diversity in reclaimed soils in this particular ecosystem, given that SOC is a key resource necessary for the majority of terrestrial microbial communities (Cai et al., 2016; Zumsteg et al., 2012). RDA analysis further revealed that the relative abundance of the dominant soil bacteriaProteobacteria was positively correlated with SOC. This is consistent with prior work demonstrating that bacterial community composition in semi-arid agricultural ecosystems is driven by SOC (Cheng et al., 2017). Soil pH is also thought to be an important determinant of soil bacteria community structure, diversity, and richness in a range of ecosystems (Fierer, \& Jackson, 2006; Ramirez et al., 2014). We observed significant positive correlations between bacterial community structure (Chao1, Observed species, and Shannon indices) and soil pH (Table S). Overall, soil pH explains 42.20\% of the total variation of soil bacterial communities at the phylum level (Figure 7), suggesting that $\mathrm{pH}$ is of critical importance in shaping the structure of bacterial communities in reclaimed desertified soil. In addition to $\mathrm{SOC}$ and $\mathrm{pH}$, elevated nutrient levels in cultivated land may ameliorate nutrient-dependent constraints on bacterial growth and function in otherwise nutrient-poor desert soils, thus driving increased bacterial diversity in crop ecosystems.

Herein, Ascomycota species were the dominant fungi and were positively correlated with SOC and TN (Figure 7). Soil fungal community diversity has been reported to be associated with nitrate-nitrogen, TN, SOC, and pH (Ferreira, Leite, de Araujo, \& Eisenhauer, 2016; Huhe, Chen, Hou, Wu, \& Cheng, 2017), in line with our data. Relative to bacteria or archaea, fungal survival is more dependent upon carbon and nitrogen sources (Schmidt, Nemergut, Darcy, \& Lynch, 2014). Soil nitrogen and SOC regulate the structure of both bacterial and fungal communities in the soil. Overall, our data suggest that soil physicochemical properties are significantly altered following desert land reclamation, thereby increasing fungal and bacterial diversity, which is essential to ensure crop ecosystem stability and long-term sustainable land use.

\section{CONCLUSIONS}

In conclusion, we herein found that winegrape planting can significantly improve soil chemical properties and can thereby significantly alter soil microbial community composition and diversity. SOC, TN, and available potassium levels rose following DL reclamation. Relative to DL soils, CS, M, C, and IR soils exhibited significantly altered soil bacterial community diversity, with the greatest increase in such diversity in $\mathrm{C}$ soil samples. Analyses of the relationships between soil chemistry and the microbial communities therein revealed that $\mathrm{pH}, \mathrm{TN}, \mathrm{TK}$, and SOC were the primary determinants of microbial communities associated with these different land use types. Overall, our data offer a new perspective on approaches to the sustainable use of land resources in desertified regions, with viticulture being one such sustainable land reclamation practice. The development of local economic forests can further reduce desertification and improve local incomes, thereby simultaneously alleviating poverty and land degradation in China and throughout the world.

\section{DATA AVAILABILITY STATEMENT}

The data that support the findings of this study are available from the corresponding author upon reasonable request.

\section{ACKNOWLEDGEMENTS}

This study was supported by the National Key Research and Development Project (2019YFD1002500), Key Research and Development Project of Shaanxi Province (2020ZDLNY07-08). We thank Jianhua Liu (Hongsibu District Agriculture and Rural Affairs Bureau of Wuzhong Municipality) for the useful help in soil sample collection.

\section{ADDITIONAL INFORMATION}


The authors declare no competing financial interests.

\section{AUTHOR CONTRIBUTION STATEMENT}

L.Z. designed the research and conducted the soil sample collection. L.Z. analyzed the data and wrote the article. All authors contributed to the ideas and text contained in the manuscript.

\section{REFERENCES}

Alvarez, A., Saez, J. M., Costa, J. S. D., Colin, V. L., Fuentes, M. S., Cuozzo, S. A., ... Amoroso, M. J. (2017). Actinobacteria: Current research and perspectives for bioremediation of pesticides and heavy metals. Chemosphere, 166 , 41-62. https://doi.org/10.1016/j.chemosphere.2016.09.070

Anderson, M. J. (2001). A new method for non-parametric multivariate analysis of variance. Austral Ecology, 26 , 32-46. https://doi.org/10.1111/j.1442-9993.2001.01070.pp.x

Bao, S. D. (2000). Agriculture and chemistry analysis of soil. China Agriculture Press, Beijing

Bhattacharyya, R., Pandey, A. K., Gopinath, K. A., Mina, B. L., Bisht, J. K., \& Bhatt, J. C. (2014). Fertilization and Crop Residue Addition Impacts on Yield Sustainability Under a Rainfed Maize-Wheat System in the Himalayas. Proceedings of the National Academy of Sciences, India Section B: Biological Sciences, 86 , 21-32. https://doi.org/10.1007/s40011-014-0394-8

Bunemann, E. K., Bongiorno, G., Bai, Z., Creamer, R. E., De Deyn, G., de Goede, R., . . . Brussaard, L. (2018). Soil quality - A critical review. Soil Biology and Biochemistry, 120 , 105-125. https://doi.org/10.1016/j.soilbio.2018.01.030

Cai, W., Li, Y., Wang, P. F., Niu, L. H., Zhang, W. L., \& Wang, C. (2016). Revealing the relationship between microbial community structure in natural biofilms and the pollution level in urban rivers: A case study in the Qinhuai River basin, Yangtze River Delta. Water Science and Technology, 74, 1163-1176. https://doi.org/10.2166/wst.2016.224

Callahan, B. J., Mcmurdie, P. J., Rosen, M. J., Han, A. W., Johnson, A. J., \& Holmes, S. P. (2016). DADA2: high-resolution sample inference from illumina amplicon data. Nature Methods, 13 , 581-583. https://doi.org/10.1038/NMETH.3869

Carter, M. R., \& Gregorich, E. G. (2007). Soil sampling and methods of analysis. Boca Raton, FL: CRC Press. https://doi.org/10.1201/9781420005271

Chen, Y. L., Xu, T. L., Veresoglou, S. D., Hu, H. W., Hao, Z. P., Hu, Y. J., ... Chen, B. D. (2017). Plant diversity represents the prevalent determinant of soil fungal community structure across temperate grasslands in northern China. Soil Biology and Biochemistry, 110 , 12-21. https://doi.org/10.1016/j.soilbio.2017.02.015

Cheng, Z., Zhang, F., Gale, W. J., Wang, W., Sang, W., \& Yang, H. (2017). Effects of reclamation years on composition and diversity of soil bacterial communities in Northwest China. Canadian Journal of Microbiology, 64 , 28-40. https://doi.org/10.1139/cjm-2017-0362

Cheng, Z., Chen, Y., \& Zhang, F. (2018). Effect of reclamation of abandoned salinized farmland on soil bacterial communities in arid Northwest China. Science of the Total Environment, 630 , 799-808. https://doi.org/10.1016/j.scitotenv.2018.02.259

Cheng, Z., Chen, Y., \& Zhang, F. (2019). Effect of cropping systems after abandoned salinized farmland reclamation on soil bacterial communities in arid Northwest China. Soil and Tillage Research, 187, 204-213. https://doi.org/10.1016/j.still.2018.12.015

Crecchio, C., Curci, M., Pellegrino, A., Ricciuti, P., Tursi, N., \& Ruggiero, P. (2007). Soil microbial dynamics and genetic diversity in soil under monoculture wheat grown in different long-term management systems. Soil Biology and Biochemistry, 39 , 1391-1400. https://doi.org/10.1016/j.soilbio.2006.12.016 
Delgado-Baquerizo, M., Maestre, F. T., Reich, P. B., Jeffries, T. C., Gaitan, J. J., Encinar, D., ... Singh, B. K. (2016). Microbial diversity drives multifunctionality in terrestrial ecosystems. Nature Communications, 7, 10541. https://doi.org/10.1038/ncomms10541

Djukic, I., Zehetner, F., Tatzber, M., \& Gerzabek, M. H. (2010). Soil organicmatter stocks and characteristics along an alpine elevation gradient. Journal of Plant Nutrition and Soil Science, 173 , 30-38. https://doi.org/10.1002/jpln.200900027

Dominguez, M. T., Panettieri, M., Madejon, E., \& Madejon, P. (2020). Thistle crops in marginal lands after compost addition: Plant biomass and effect on soil physical, chemical and biological properties. Land Degradation 83 Development, 31 , 1167-1175. https://doi.org/10.1002/ldr.3510

Ellouze, W., Esmaeili Taheri A, Bainard, L. D., Yang, C., Bazghaleh, N., Navarro-Borrell, A., ... Hamel, C. (2014). Soil fungal resources in annual cropping systems and their potential for management. Biomed Research International, 2014, 1-15. https://doi.org/10.1155/2014/531824

Ferreira, A. C. C., Leite, L. F. C., de Araujo, A. S. F., \& Eisenhauer, N. (2016). Land-Use Type Effects on Soil Organic Carbon and Microbial Properties in a Semi-arid Region of Northeast Brazil. Land Degradation \& Development, 27, 171-178. https://doi.org/10.1002/ldr.2282

Fierer, N., \& Jackson, R. B. (2006). The diversity and biogeography of soil bacterial communities. Proceedings of the National Academy of Sciences, 103 , 626-631. https://doi.org/10.1073/pnas.0507535103

Franco-Otero, V. G., Soler-Rovira, P., Hernandez, D., Lopez-de-Sa, E. G., \& Plaza, C. (2012). Shortterm effects of organic municipal wastes on wheat yield, microbial biomass, microbial activity, and chemical properties of soil. Biology and Fertility Soils, 48 , 205-216. https://doi.org/10.1007/s00374-011-0620-y

Gao, L., Wang, R., Gao, J. M., Li, F. M., Huang, G. H., Huo, G., .. Shen, G. M. (2020). Analysis of the structure of bacterial and fungal communities in disease suppressive and disease conducive tobacco-planting soils in China. Soil Research, 58 , 35-40. https://doi.org/10.1071/sr19204

Gong, L., He, G., \& Liu, W. (2016). Long-term cropping effects on agricultural sustainability in Alar oasis of Xinjiang, China.Sustainability, 8 , 1-11. https://doi.org/10.3390/su8010061

Hendrix, M. S. (2000). Evolution of mesozoic sandstone compositions, southern Junggar, northern Tarim, and western Turpan basins, northwest China: A detrital record of the ancestral Tian Shan. Journal of Sedimentary Research, 70 , 520-532. https://doi.org/10.1306/2DC40924-0E47-11D7-8643000102C1865D

Huhe., Chen, X. J., Hou, F. J., Wu, Y. P., \& Cheng, Y. X. (2017). Bacterial and fungal community structures in Loess Plateau grasslands with different grazing intensities. Frontiers in Microbiology, 8 , 606. https://doi.org/10.3389/fmicb.2017.00606

Kemp, P. F., \& Aller, J. Y. (2004). Bacterial diversity in aquatic and other environments: what $16 \mathrm{~S}$ rDNA libraries can tell us. FEMS Microbiology Ecology, 47 , 161-177. https://doi.org/10.1016/S01686496(03)00257-5

Kerfahi, D., Tripathi, B. M., Dong, K., Go, R., \& Adams, J. M. (2016). Rainforest conversion to rubber plantation may not result in lower soil diversity of bacteria, fungi, and nematodes. Microbial Ecology, 72 , 359-371. https://doi.org/10.1007/s00248-016-0790-0

Kowalchuk, G. A., Buma, D. S., de Boer, W., Klinkhamer, P. G. L., \& van Veen, J. A. (2002). Effects of above-ground plant species composition and diversity on the diversity of soil-borne microorganisms. Antonie van Leeuwenhoek, 81 , 509-520. https://doi.org/10.1023/A:1020565523615

Koberl, M., Muller, H., Ramadan, E. M., \& Berg, G. (2011). Desert farming benefits from microbial potential in arid soils and promotes diversity and plant health. PLoS ONE, 6, e24452. https://doi.org/10.1371/journal.pone.0024452 
Lange, M., Eisenhauer, N., Sierra, C. A., Bessler, H., Engels, C., Griffiths, R. I., .. Gleixner, G. (2015). Plant diversity increases soil microbial activity and soil carbon storage. Nature Communications, 6 , 1-8. https://doi.org/10.1038/ncomms7707

Lauber, C. L., Hamady, M., Knight, R., \& Fierer, N. (2009). Pyrosequencingbased assessment of soil pH as a predictor of soil bacterial community structure at the continental scale. Applied and Environmental Microbiology, 75 , 5111-5120. https://doi.org/10.1128/AEM.00335-09

Li, H., Chi, Z. F., Li, J. L., Wu, H. T., \& Yan, B. X. (2019). Bacterial community structure and function in soils from tidal freshwater wetlands in a Chinese delta: Potential impacts of salinity and nutrient. Science of the Total Environment, 696 , 134029. https://doi.org/10.1016/j.scitotenv.2019.134029

Li, J. B., Liu, G. M., Kwak, J-H., Chang, S. X., Gao, H. C., Wu, Q. C., . . Chen J. L. (2020). Reclamation of desert land to continuous cotton cropping affects soil properties and microbial communities in the desert-oasis ecotone of Xinjiang, China. Journal of Soils and Sediments, 20 , 862-873. https://doi.org/10.1007/s11368019-02469-2

Li, J. B., Pokharel, P., Liu, G. M., \& Chen, J. L. (2020). Reclamation of desert land to different landuse types changes soil bacterial community composition in a desert-oasis ecotone. Land Degradation $\mathcal{E}^{3}$ Development, 32 , 1389-1399. https://doi.org/10.1002/ldr.3803

Li, X. G., Ding, C. F., Zhang, T. L., \& Wang, X. X. (2014). Fungal pathogen accumulation at the expense of plant-beneficial fungi as a consequence of consecutive peanut monoculturing. Soil Biology $\mathscr{E}_{3}$ Biochemistry, 72 , 11-18. 10.1016/j.soilbio.2014.01.019

Liu, X. B., Liu, J. D., Xing, B. S., Herbert, S. J., Meng, K., Han, X. Z., \& Zhang, X. Y. (2005). Effects of long-term continuous cropping, tillage, and fertilization on soil organic carbon and nitrogen of black soils in China. Communications in Soil Science and Plant Analysis, 36, 1229-1239. https://doi.org/10.1081/CSS200056917

Lu, R. (1999). Analytical methods of soil and agricultural chemistry. China Agricultural Science and Technology Press, Beijing

Ma, J. Y., Sun, W., Sun, H. L., \& Wang, S. M. (2012). Stable carbon isotope characteristics of desert plants in the Junggar Basin, China.Ecological Research, 27 , 115-124. https://doi.org/10.1007/s11284-011-0878-4

Maestre, F. T., Delgado-Baquerizo, M., Jeffries, T. C., Eldridge, D. J., Ochoa, V., Gozalo, B., ... Singh, B. K. (2015). Increasing aridity reduces soil microbial diversity and abundance in global drylands. Proceedings of the National Academy of Sciences, 112 , 15684-15689. https://doi.org/10.1073/pnas.1516684112

Maron, P. A., Sarr, A., Kaisermann, A., Leveque, J., Mathieu, O., Guigue, J., ... Ranjard, L. (2018). High microbial diversity promotes soil ecosystem functioning. Applied and Environmental Microbiology, 84 , e02738-17. https://doi.org/10.1128/AEM.02738-17

Meng, M., Lin, J., Guo, X., Liu, X., Wu, J., Zhao, Y., \& Zhang, J. (2019). Impacts of forest conversion on soil bacterial community composition and diversity in subtropical forests. Catena, 175 , 167-173. https://doi.org/10.1016/j.catena.2018.12.017

McArdle, B. H., \& Anderson, M. J. (2001). Fitting multivariate models to community data: a comment on distance-based redundancy analysis.Ecology, 82 , 290-297. https://doi.org/10.1890/00129658(2001)082[0290:fmmtcd]2.0.co;2

Morvan, X., Saby, N. P., Arrouays, D., Le Bas, C., Jones, R. J., Verheijen, F. G., . . . Kibblewhite, M. G. (2008). Soil monitoring in Europe: a review of existing systems and requirements for harmonisation.Sci Total Environ, 391 (1), 1-12. https://doi.org/10.1016/j.scitotenv.2007.10.046

Mouazen, A. M., Steffens, M., \& Borisover, M. (2016). Reflectance and fluorescence spectroscopy in soil science-Current and future research and developments. Soil and Tillage Research, 155 , 448-449. 
https://doi.org/10.1016/j.still.2015.09.002

Nanganoa, L. T., Okolle, J. N., Missi, V., Tueche, J. R., Levai, L. D., \& Njukeng, J. N. (2019). Impact of different land-use systems on soil physicochemical properties and macrofauna abundance in the humid tropics of Cameroon. Applied and Environmental Soil Science, 2019 , 1-9. https://doi.org/10.1155/2019/5701278

Neilson, J. W., Califf, K., Cardona, C., Copeland, A., van Treuren, W., Josephson, K. L., .. Maier, R. M. (2017). Significant impacts of increasing aridity on the arid soil microbiome. Systems, 2 , e00195-16. https://doi.org/10.1128/mSystems.00195-16

Oliver, D. P., Bramley, R. G. V., Riches, D., Porter, I., \& Edwards, J. (2013). Review: soil physical and chemical properties as indicators of soil quality in Australian viticulture. Australian Journal of Grape and Wine Research, 19 (2), 129-139. https://doi.org/10.1111/ajgw.12016

Porras-Alfaro, A., Herrera, J., Natvig, D. O., Lipinski, K., \& Sinsabaugh, R. L. (2011). Diversity and distribution of soil fungal communities in a semiarid grassland. Mycologia, 103, 10-21. https://doi.org/10.3852/09-297

Prober, S. M., Leff, J. W., Bates, S. T., Borer, E. T., Firn, J., Harpole, W. S., .. Fierer, N. (2015). Plant diversity predicts beta but not alpha diversity of soil microbes across grasslands worldwide. Ecology Letters, 18 , 85-95. https://doi.org/10.1111/ele.12381

Qiao, H. X., Zhang, L. H., Shi, H. T., Song, Y. Z., \& Bian, C. Z. (2018). Astragalus affects fecal microbial composition of young hens as determined by 16S Rrna sequencing.AMB Express, 8 , 70. https://doi.org/10.1186/s13568-018-0600-9

Ramirez, K. S., Leff, J. W., Barberan, A., Bates, S. T., Betley, J., Crowther, T. W., .. Fierer, N. (2014). Biogeographic patterns in belowground diversity in New York City's Central Park are similar to those observed globally. Proceedings. Biological Sciences, 281, 20141988. https://doi.org/10.1098/rspb.2014.1988

Salama, F. M., Abd El-Ghani, M. M., El-Tayeh, N. A., Amro, A., \& Abdrabbu, H. S. (2017). Correlations between soil variables and weed communities in major crops of the desert reclaimed lands in southern Egypt. Rendiconti Lincei, 28 (2), 363-378. https://doi.org/10.1007/s12210-017-0604-4

Schmidt, S. K., Nemergut, D. R., Darcy, J. L., \& Lynch, R. (2014). Do bacterial and fungal communities assemble differently during primary succession? Molecular Ecology, 23 , 254-258. https://doi.org/10.1111/mec.12589

Segata, N., Izard, J., Waldron, L., Gevers, D., Miropolsky, L., Garrett, W. S., \& Huttenhower, C. (2011). Metagenomic biomarker discovery and explanation. Genome Biology, l1 , R60. https://doi.org/10.1186/gb2011-12-6-r60

Sharma, N. K., Singh, R. J., Mandal, D., Kumar, A., Alam, N. M., \& Keesstra, S. (2017). Increasing farmer's income and reducing soil erosion using intercropping in rainfed maize-wheat rotation of Himalaya, India. Agriculture, Ecosystems \& Environment, 247 , 43-53. https://doi.org/10.1016/j.agee.2017.06.026

Smith, B. F. L., \& Bain, D. C. (1982). A sodium hydroxide fusion method for the determination of total phosphate in soils. Communications in Soil Science and Plant Analysis, 13 , 185-190. https://doi.org/10.1080/00103628209367257

Szoboszlay, M., Dohrmann, A. B., Poeplau, C., Don, A., \& Tebbe, C. C. (2017). Impact of land-use change and soil organic carbon quality on microbial diversity in soils across Europe. FEMS Microbiology Ecology, 93 , 1-12. https://doi.org/10.1093/femsec/fix146

Thomson, B. C., Tisserant, E., Plassart, P., Uroz, S., Griffiths, R. I., Hannula, S. E., .. Lemanceau, P. (2015). Soil conditions and land use intensification effects on soil microbial communities across a range of European field sites. Soil Biology and Biochemistry, 88 , 403-413. https://doi.org/10.1016/j.soilbio.2015.06.012 
Tian, Q., Taniguchi, T., Shi, W. Y., Li, G., Yamanaka, N., \& Du, S. (2017). Land-use types and soil chemical properties influence soil microbial communities in the semiarid Loess Plateau region in China.Scientific Reports, 7 , 45289. https://doi.org/10.1038/srep45289

Tosi, M., Correa, O. S., Soria, M. A., Vogrig, J. A., Sydorenko, O., \& Montecchia, M. S. (2016). Land-use change affects the functionality of soil microbial communities: A chronosequence approach in the Argentinian Yungas. Applied Soil Ecology, 108 , 118-127. https://doi.org/10.1016/j.apsoil.2016.08.012

Wang, B., Zhang, C., Liu, J., Zeng, X., Li, F. R., Wu, Y. C., .. Jia, Z. J. (2012). Microbial community changes along a land-use gradient of desert soil origin.Pedosphere, 22 , 593-603. https://doi.org/10.1016/S1002-0160(12)60044-7

Wasmund, K., Mussmann, M., \& Loy, A. (2017). The life sulfuric: Microbial ecology of sulfur cycling in marine sediments.Environmental Microbiology Reports, 9 , 323-344. https://doi.org/10.1111/1758-2229.12538

Wu, W. C., Dong, C. X., Wu, J. H., Liu, X. W., Wu, Y. X., Chen, X. B., \& Yu, S. X. (2017). Ecological effects of soil properties and metal concentrations on the composition and diversity of microbial communities associated with land use patterns in an electronic waste recycling region. Science of Total Environment, 601 , 57-65. https://doi.org/10.1016/j.scitotenv.2017.05.165

Xu, C. Y., Wang, T., Jia, C. B., \& Guo, Y. (2020). Effects of different desert plants on the soil chemical properties and enzyme activities in helanshan Eatern region. Ecology and Environment, 29 , 2346-2354. https://doi.org/10.16258/j.cnki.1674-5906.2020.12.005

Yang, H. C., Zhang, F. H., Chen, Y., Xu, T. B., Cheng, Z. B., \& Liang, J. (2016). Assessment of reclamation treatments of abandoned farmland in an arid region of China. Sustainability, 8 , 1183. https://doi.org/10.3390/su8111183

Yang, R., Du, Z., Kong, J., Su, Y., Xiao, X., Liu, T., . . . Fan, G. (2019). Patterns of soil nitrogen mineralization under a land use change from desert to farmland. European Journal of Soil Science . https://doi.org/10.1111/ejss.12823

Zumsteg, A., Luster, J., Goransson, H., Smittenberg, R. H., Brunner, I., Bernasconi, S. M., ... Frey, B. (2012). Bacterial, archaeal and fungal succession in the forefield of a receding glacier. Microbial Ecology, 63 , 552-564. https://doi.org/10.1007/s00248-011-9991-8

\section{FIGURE and TABLE CAPTIONS}

Figure 1 The study site and the distribution of 4 vineyards within this region. A, Cabernet Sauvignon (CS). B, Merlot (M).C, Chardonnay (C). D, Italian Riesling (IR). Soil samples from CS, M, and C vineyards were collected from Huida Chateau, while IR vineyard soil samples were collected from the Xiaojiayao winegrapes planting area.

Figure 2 Venn diagrams demonstrating the shared and unique bacterial and fungal sequences associated with different land-use patterns. (a), bacteria; (b), fungi. CS, Cabernet Sauvignon; M, Merlot; C, Chardonnay; IR, Italian Riesling; DL, desert land.

FIGURE 3 The relative abundance of major bacterial and fungal taxonomic groups at the phylum level across the five land-use types. (a), bacteria; (b), fungi. CS, Cabernet Sauvignon; M, Merlot; C, Chardonnay; IR, Italian Riesling; DL, desert land.

FIGURE 4 Non-metric multidimensional scaling (NMDS) ordination for soil bacterial and fungal communities associated with different land-use types. (a), bacteria; (b), fungi. CS, Cabernet Sauvignon; M, Merlot; C, Chardonnay; IR, Italian Riesling; DL, desert land.

FIGURE 5 Hierarchical clustering analysis of bacterial and fungal community structure. The panel on the right is a stacked histogram of the top 10 most abundant genera. (a), bacteria; (b), fungi. CS, Cabernet Sauvignon; M, Merlot; C, Chardonnay; IR, Italian Riesling; DL, desert land. 
FIGURE 6 Taxonomic hierarchical relationships from the phylum to species level in bacterial and fungal communities. Node sizes correspond to average relative taxa abundance. Hollow nodes correspond to taxa for which there were no significant differences between groups, whereas colored nodes correspond to taxa that differed significantly between groups, with a higher abundance in grouped samples corresponding to a given color. Letters correspond to the names of the taxa that differed significantly between groups. (a), bacteria; (b), fungi. CS, Cabernet Sauvignon; M, Merlot; C, Chardonnay; IR, Italian Riesling; DL, desert land.

FIGURE 7Redundancy analysis (RDA) of chemical parameters associated with the five land-use types. (a), bacteria; (b), fungi. TN, total nitrogen; TP, total phosphorus; TK, total potassium; SOC, soil organic carbon.

TABLE 1 Soil properties associated with different land-use types

Notes: Values are mean +- standard deviation $(\mathrm{n}=3)$; different letters indicate significant differences $(p$ $<0.05$ ) among different land-use types based on a one-way ANOVA followed by a Duncan test. $P$ values less than 0.05 indicate significance and are in italics. Abbreviations: CS, Cabernet Sauvignon; M, Merlot; C, Chardonnay; IR, Italian Riesling; DL, desert land. TN, total nitrogen; TP, total phosphorus; TK, total potassium; SOC, soil organic carbon.

TABLE 2 Soil microbial community alpha diversity indices associated with different land-use types

Notes: Values are mean + - standard deviation $(\mathrm{n}=3)$; different letters indicate significant differences $(p<$ 0.05 ) among different land-use types based on a one-way ANOVA followed by a Duncan test. $P$ values less than 0.05 indicate significance and are in italics. Abbreviations: CS, Cabernet Sauvignon; M, Merlot; C, Chardonnay; IR, Italian Riesling; DL, desert land.

TABLE 3 Permutational multivariate analysis of variance (PERMANOVA) table for bacterial and fungal community composition differences associated with different land-use types

TABLE S Pearson correlation of chemical parameters associated with the soil microbial diversity $(\mathrm{n}=15)$

Notes: ${ }^{*} p<0.05 .{ }^{* *} p<0.01$.

Abbreviations: TN, total nitrogen; TP, total phosphorus; TK, total potassium; SOC, soil organic carbon.

\section{Hosted file}

Figures and Tables.pdf available at https://authorea.com/users/408889/articles/518722-

evidence-of-sustainable-land-use-the-reclamation-of-desertified-lands-to-plant-vineyards 